\title{
2017 Geneva Declaration \\ Ten Years Promoting Healthy Lives and Well-being for All
}

\author{
International College of Person Centered Medicine \\ Declaration adopted by the participants of the 10th Geneva Conference on Person Centered Medicine and \\ released by the Board of the International College of Person Centered Medicine on 30 June 2017.
}

\section{Preamble}

The International College of Person-centered Medicine celebrates at its 2017 Geneva Conference ten years of constructing person- and people-centered medicine and health, conceptually and procedurally, in close collaboration with the World Medical Association, the World Health Organization, the International Council of Nurses, and the International Alliance of Patients' Organizations, among other global health institutions. This maturational process has as milestones the main themes of the unfolding Geneva Conferences, i.e., Conceptual Explorations, From Concepts to Actions, Team Work, Articulating Clinical Medicine and Public Health, Research, Chronic Diseases, Integrated Care, Primary Care, and Life Course. The present Geneva Conference's main theme, Celebrating Ten Years of Promoting Healthy Lives and Well-being for All, highlights the United Nations Sustainable Development Goal on Health. This institutional journey has been complemented by International Congresses in Zagreb, Buenos Aires, London, and Madrid focused respectively on professional training, humanistic and interdisciplinary care, primary care, and medical education.

The solidity of the journey has been supported by scholarly developments. One has been the establishment of the International Journal of Person Centered Medicine in cooperation with the Buckingham University Press in London. This has stimulated research and facilitated dissemination of literature in this emerging field, originating from across the world. Another has been a books program, with a first volume on Person Centered Psychiatry published by Springer, Switzerland, under the auspices of the ICPCM, the co-sponsorship of the World Psychiatric Association, and authorship participation of 18 of the WPA scientific sections.

Among the programmatic research efforts sponsored by the ICPCM, is that aimed at the development of a Personcentered Integrative Diagnosis model. Its structural levels encompass health status (from illness to wellbeing), health contributors (risk and protective factors), and health experience and values. It has found practical application in the Latin American Guide for Psychiatric Diagnosis, published by the Latin American Psychiatric Association for the use of health professionals in that world region.

Another ICPCM research landmark, with support from the World Health Organization, has encompassed the systematic conceptualization of person centered medicine and the development and validation of a prototype Person-centered Care Index. It elucidated eight key concepts underlying person centered medicine, as follows: 1) Ethical commitment, 2) Holistic framework, 3) Cultural awareness and responsiveness, 4) Relational and communicational focus (for which the establishment of empathy is crucial), 5) Individualized care, 6) Common ground among clinicians, patient and family for joint diagnostic understanding and shared decision making, 7) people-centered and integrated health systems, and 8) Personcentered education and health research.

The person-centered care movement was powerfully stimulated by awareness of the pervasive dehumanization of medicine, denoted by hyperbolic attention to organs and diseases (neglecting the person's totality, values and context) and commercialization of clinical care, leading to impoverished communication between health professionals and patients and their families. Also alarming has been the neglect of the health of doctors and other health professionals as revealed by high levels of professionals' burn out.

The Tenth Geneva Conference offered an opportunity to review the above efforts, achievements and challenges, while addressing the significance for person centered medicine of the United Nations Sustainable Development Goals, in particular the Health goal, coached as ensuring healthy lives and well-being for all, consistent with WHO's compelling definition of health. This allowed the pointed examination of a range of health promotion conceptual and procedural efforts, including WHO's Ottawa and Shanghai Declarations and ongoing global programs on people-centered integrated health services, global work force, chronic diseases, mental health, and environmental and social determinants of health as well as the above mentioned ICPCM Geneva Declarations, research efforts, and publications. It also made possible to pay attention to pressing world challenges such as the person-centered management of the health consequences of natural, man-made and economic disasters and the health of refugees, migrants, and host country citizens.

\section{Call to Action}


The International College of Person Centered Medicine will continue building person-centeredness in medicine and health as theory, practice and journey, articulating science, experience and humanism. Priority action will be focused on the following:

1. Sensitizing and enabling health professionals, especially younger ones, on the person-centered approach, ethical commitment, and the contributions of biological, psychological, social, financial, political, cultural and spiritual factors to the understanding, restoration and promotion of health.

2. Highlighting the value of multidisciplinary team work and of collaboration with organizations of patients, relatives, caregivers, and advocates.

3. Promoting integrated care at all levels, including the integration of primary, mental, and specialty care and intersectoral coordination, advancing the articulation of person-centered clinical care and people centered public health.

4. Cultivating productive and fulfilling clinical communication with particular attention to the understanding, training on and implementation of empathy.

5. Advancing person-centered health professional education on individualized care and the establishment of common ground with patients and families for joint diagnostic understanding and shared decision making.

6. Organizing the next editions of the Geneva Conferences and International Congresses of Person Centered Medicine, using the evaluations of previous events.

7. Continuing the publication of the International Journal of Person Centered Medicine, preparing a volume on Person Centered Medicine, enhancing the institutional website as platform for professional and public health education, and considering the development of person-centered e-health aids and data-based projects.

8. Advancing scholarly projects on person-centered diagnosis, clinical care guidelines, and conceptualization and measurement of person centered medicine and exploring new projects on addressing professional burn-out, person-centered medical education and people-centered health services and public health.

9. Opening new opportunities for individual and organizational membership, health discipline networks, and regional continental networks.

10. Collaborating with the World Health Organization, the World Medical Association and like-minded institutions on the fulfillment of the Sustainable Development Goals, people-centered integrated health systems, and person-centered health care and professional health education.

While celebrating ten years of accomplishments, the International College of Person Centered Medicine reaffirms its commitment to continued dedicated and creative work in collaboration with all relevant institutions to advance the fulfillment of whole person's health and well-being across the world. 